\title{
Improvement of operation of steam cushion system for sensible thermal energy storage
}

\author{
Ryszard Zwierzchowski ${ }^{1, *}$ \\ ${ }^{1}$ Department of Heating and Gas Engineering, Faculty of Building Services, Hydro \\ and Environmental Engineering, Warsaw University of Technology, ul. Nowowiejska 20, \\ 00-653 Warsaw, Poland
}

\begin{abstract}
The paper contains a method for improvement of operation of steam cushion system including its energy savings analyses, for a Thermal Energy Storage (TES) tank. Energy savings analyses were performed using operational data from selected Combined Heat and Power plants, which supply heat to large cities in Poland and are furnished with the TES. The role of the steam cushion system in the TES tank is to prevent the stored water against absorbing oxygen from atmospheric air. In the TES tank, which is a non-pressure tank, oxygen from atmospheric air could penetrate to the network water through the surge chamber and safety valves. The steam pressure under the roof is generated from technological steam injected under the roof. Energy savings in the steam cushion system are generated by using an appropriate technical solution for the upper orifice and suction pipe for circulation water, i.e., to make it movable through the use of pontoons. An isolating buffer layer is created at the top of the tank with very small convective and turbulent heat transport, which causes limited heat transfer from steam bed to the stored water in the tank. This results in heat flux of approximately $10 \%$ of the heat flux that occurs in the typical technical solution of the upper orifice and suction pipe for circulation water in the TES tank. This technology offers great opportunities to improve the operating conditions of District Heating System, cutting energy production costs and emissions of pollutants to the atmosphere.
\end{abstract}

\section{Introduction}

District Heating Systems (DHS) in Poland, which are supplied with heat from District Heating plants (DHp) or Combined Heat and Power plants (CHPp), have been undergoing intensive modernization over the last twenty years. These modernization processes usually concern energy generation in DHp or CHPp and heat distribution through the District Heating Network (DHN). Recently, in order to improve the operating conditions of DHS and to increase their efficiency and availability, consideration has been given to introducing Thermal Energy Storage (TES) systems. Therefore any attempt at this time to modernize the hydraulic systems in DHp and CHPp should include or at least consider the introduction of TES.

\footnotetext{
*Corresponding author: ryszard.zwierzchowski@pw.edu.pl
} 
Thermal energy storage is viewed as one of most important advanced energy technologies to correct mismatches between the supply and demand of energy. TES in principle includes a "temporary storage medium" in high (heating) or low (cooling) temperature for later use [1]. A sensible TES system consists of a tank, a storage medium and inlet/outlet devices. Energy in this TES system is stored by changing the temperature of the storage medium and the amount of energy is proportional to the difference between the storage inlet and outlet temperatures, the mass of the storage medium and its heat capacity [2-4]. Implementation of TES in DHS is treated as innovatory technology in the Polish District Heating sector. TES technology offers big, new opportunities to improve the operating conditions of DHS, i.e., to cut heat and electricity production costs and emissions of pollutants to the atmosphere, and to boost energy security for consumers [5].

\section{System description}

Energy savings analyses for the operation of a steam cushion for a TES tank were performed for the CHPp Siekierki in Warsaw. This TES is the first big system in Poland, i.e. the tank has a capacity in excess of $10000 \mathrm{~m}^{3}$ and has been in operation since March 2009. This CHPp is the biggest CHPp in Poland and the second biggest in Europe. Installed heating and electrical capacities are $2078 \mathrm{MW}_{\text {th }}$ and $622 \mathrm{MW}_{\mathrm{e}}$ respectively. CHPp Siekierki has been in operation since 1961 and presently consists of:

- a "Blocks Part", i.e., three Heating Blocks (Blocks Nos. 7, 9 and 10 with nominal electrical capacity of $110 \mathrm{MW}_{\mathrm{e}}$ and heating capacity of $175 \mathrm{MW}_{\text {th }}$ each),

- a condensing turbine with heat extraction with a nominal electrical capacity of $125 \mathrm{MW}_{\mathrm{e}}$

- a "Collector Part" (four steam boilers and five steam turbines with a total nominal electrical capacity of $170 \mathrm{MW}_{\mathrm{e}}$ ),

- six water boilers with a total nominal heating capacity of $884 \mathrm{MW}_{\text {th. }}$.

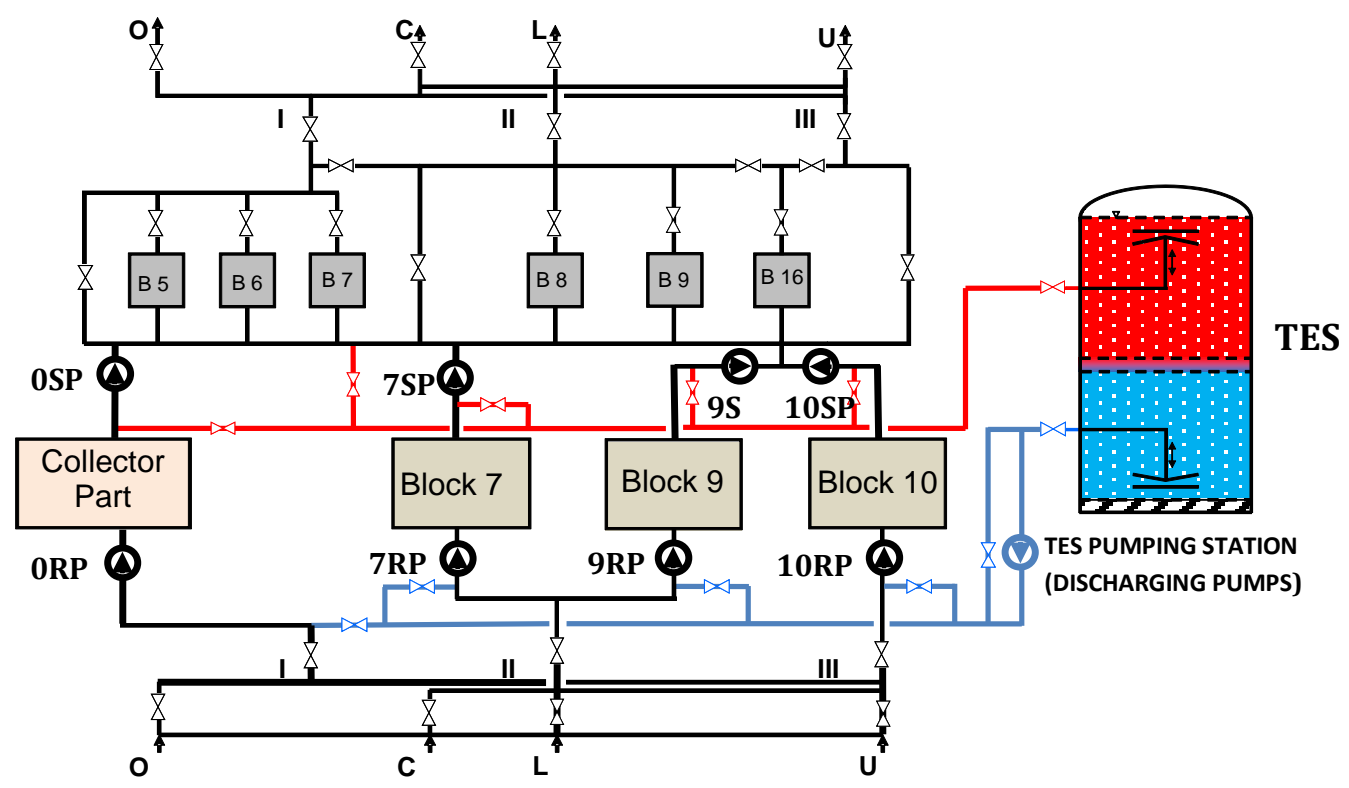

Fig. 1. Schematic layout of the analyzed CHPp - Warsaw CHPp Siekierki. 
The Blocks Part of CHPp Siekierki consists of base load units. During the heating season they are in continuous operation while in summer due to the much lower heat demand only one Heating Block is in operation. The Collector Part is mainly in operation when heat demand increases significantly, i.e. when the external air temperature drops below zero. The water boilers are used as peak load boilers and are mainly in operation when the temperature drops below $-15^{\circ} \mathrm{C}$. Of course, some CHPp units could operate when heat demand from heat consumers is low or non-existent, but electricity demand is high or electricity prices are profitable [6].

Fig. 1 shows a schematic layout of CHPp Siekierki in Warsaw. The CHPp is hooked up to the DHN (supply and return side) through mains piping marked by $\mathrm{O}, \mathrm{C}, \mathrm{L}$ and $\mathrm{U}$. Return water pumps are marked RP, supply pumps SP, water boilers B.

The TES, i.e. thermally stratified, sensible heat storage, was designed in 2007 , built in 2008 and after start-up and commissioning periods has been in operation since March 2009. The TES tank was designed as a non-pressure tank and is hooked up to the DHS through the TES Pumping Station by Discharging Pumps. Network water stored in the TES tank is protected against oxygen absorption from atmosphere air by a steam cushion system.

\section{Characteristics of the steam cushion system}

The role of the steam cushion system in the TES tank is to prevent stored water from absorbing oxygen from atmospheric air. The quality of the water in the TES tank must fulfill the appropriate standards for water circulating in the District Heating Network (DHN). One of the most important indicators is the concentration of oxygen dissolved in the water circulating in DHN. Polish standards stipulate a maximum permissible oxygen concentration of $30 \mathrm{ppm}$. Excessive oxygen dissolved in the water could cause corrosion of equipment (including the TES tank), accessories and piping for the network water. In the case of the TES tank, which is a non-pressure tank, oxygen from atmospheric air could penetrate to the network water through the surge chamber and safety valves. Both valves are placed on the roof of the tank and protect the TES tank (the steam bed area, i.e. the space between the surface of the stored water and the roof of the tank) against excessive negative-pressure and over-pressure respectively. For the analyzed TES tanks permissible negative-pressure is not less than $-500 \mathrm{~Pa}$ and over-pressure is not more than $+1500 \mathrm{~Pa}$. Normal operating steam pressure in the steam bed is over-pressure:

$$
p_{s b}=+500 \mathrm{~Pa} \pm 100 \mathrm{~Pa}
$$

The steam cushion system consists of (see Fig. 2):

- suction pipe with inlet fixed to the pontoon,

- circulation pump,

- electrical heater,

- delivery pipe,

- spray nozzle,

- technological steam delivery system.

The steam pressure under the roof is generated from technological steam injected under the roof. Water circulation is needed to avoid superheated steam coming into contact with the water surface and to keep the surge chamber valve filled. The circulation water, through the circulation pump, supplies the spray nozzle, where it is mixed with technological steam and creates "steam rain" in the zone of the steam bed under the roof of the TES tank. The scheme of the steam cushion system for the TES tank is presented in Fig. 2, while detail "A", i.e. the technical solution of the upper orifice and suction pipe is shown in Fig. 3. 


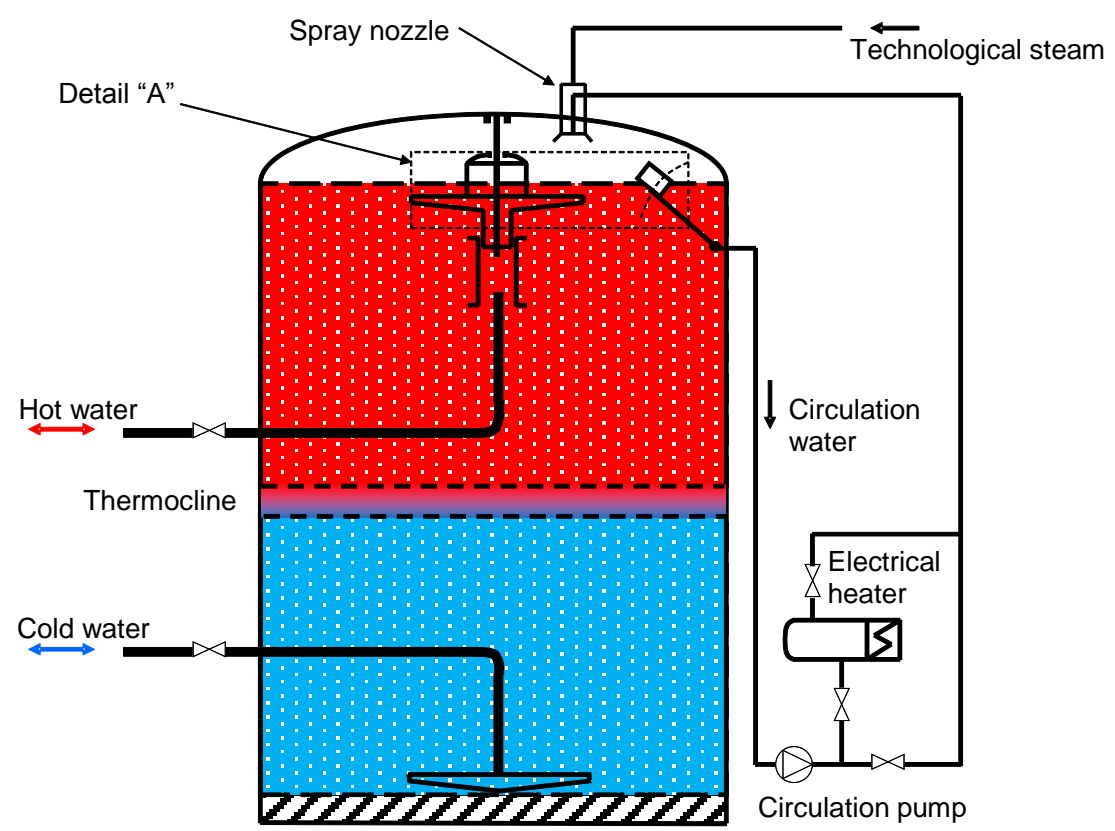

Fig. 2. Scheme of the steam cushion system which is located above the water level in the TES tank to protect network water against absorption of oxygen from atmospheric air.

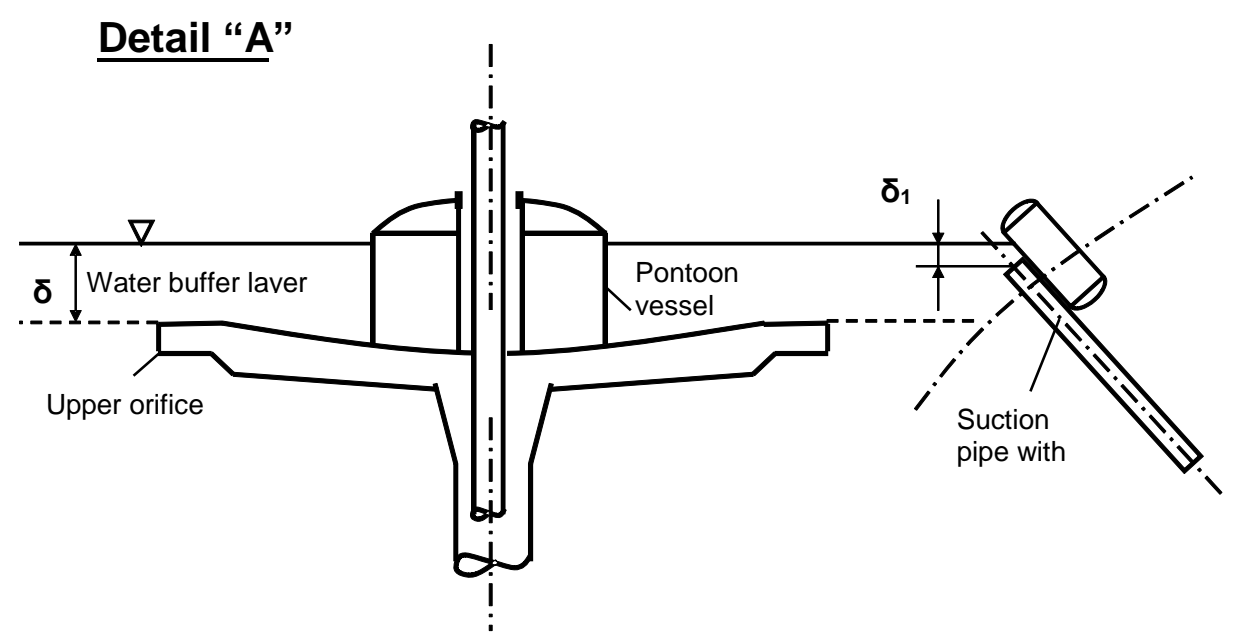

Fig. 3. Technical solution to reduce energy consumption by the steam cushion system.

\section{Energy savings for operation of the steam cushion system}

The effect of inlet geometry on stratification of the thermocline in the TES tank, which directly affects the energy efficiency of the TES system, was subject to various research by Zurigat et al. [8], Oppel et al. [9] and Wildin [10, 11]. The effect of the heat transfer through the tank wall on stratification in the TES tank was estimated as negligible by 
Murthy et al. [12]. Results of experimental and theoretical investigation of mixed and stratified hot water storage tanks are presented by Dincer and Rosen [13] and Votsis [14].

Primary analysis of energy savings for operation of the steam cushion for the TES tank was performed for CHPp Siekierki in Warsaw. Additional analysis to confirm those results was done for the TES tank in CHPp Bialystok, which has approximately $1 / 3$ the volume of the tank in Warsaw and has been in operation since autumn 2011. The analyzed steam cushion systems share the same technical construction.

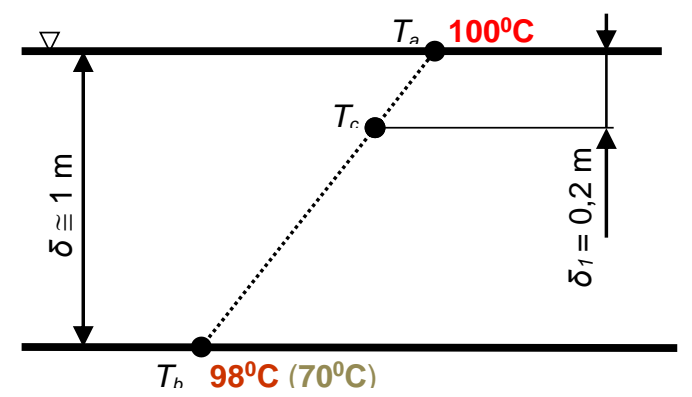

Fig. 4. Temperature distribution in the buffer layer of the steam cushion system.

Fig. 4 presents temperature distribution in water buffer layer of the steam cushion system. Assuming that convective and turbulent heat transport is extremely limited inside of the buffer layer, heat transfer from steam bed, i.e. interphase surface to the inside of the hot water stored in the tank, could be calculated from the heat conductivity equation with an appropriate correction factor (intensity of heat transport coefficient in the water buffer layer).

Unitary heat rate $\dot{q}$ in the water buffer layer from condensing steam (in the steam bed under the roof of the tank) to the surface of the water below the buffer layer with thickness $\delta$, could be calculated from the following equation:

$$
\dot{q}=\frac{\lambda}{\delta}\left(T_{a}-T_{b}\right) \cdot i_{h t}
$$

where:

$\lambda \cong 0,68 \mathrm{~W} /(\mathrm{m} \mathrm{K})-$ average heat conduction coefficient for water,

$T_{a}, T_{b}$ - temperature of the surface of the water which contacts the steam bed and water in the tank at the depth $\delta$, see Fig. 4 ,

$T_{c}$ - temperature of the water in the buffer layer at the depth $\delta_{I}$ (from that point water is taken to the circulation pump of the steam cushion system),

$i_{h t}-$ intensity of the heat transport coefficient in the water buffer layer.

The intensity of the heat transport coefficient $i_{h t}$ indicates how intensive the heat transfer is in comparison to heat conduction in the water buffer layer. This coefficient takes into consideration the intensity of convective and turbulent heat transport.

Coefficient $i_{h t}$ should be made as small as possible in order to reduce technological steam consumption in the steam cushion system. When the coefficient $i_{h t}$ equals 1 that means that heat transport is by conduction only. The technical solution presented in Fig. 2 and Fig. 3 makes it possible to significantly reduce the value of the coefficient $i_{h t}$ in comparison to the typical construction of the upper orifice and inlet of the suction pipe. 
Operational data were analyzed for the two TES tanks in question, furnished with steam cushion systems, as schematically presented in Fig. 2. These TES are:

1. TES in a Warsaw CHP plant (operational since spring 2009)

- type

- tank capacity

- diameter, $D_{\text {int }}$

- height, $H$

- water temperature (hot/cold) water, non-pressurized

$30400 \mathrm{~m}^{3}$

$30 \mathrm{~m}$

$43 \mathrm{~m}$

$98 / 40^{\circ} \mathrm{C}$

2. TES in Bialystok CHP plant (operational since autumn 2011)

- type

- tank capacity

- diameter

- height

- water temperature (hot/cold) water, non-pressurized

$12800 \mathrm{~m}^{3}$

$21 \mathrm{~m}$

$37 \mathrm{~m}$

$98 / 40^{\circ} \mathrm{C}$

Using the collected operational parameters of the steam cushion systems, i.e. steam consumption (heating power delivered to steam bed) and temperature $T_{c}$ of circulation water in the system, the coefficient of heat transport intensity $i_{h t}$ was estimated:

○ $i_{h t}=3-6$ (average value is approx. $i_{h t}=4.5$ ) [6],

$\circ i_{h t} \cong 50$ (for typical technical solution of upper orifice and suction pipe for circulation water) [6].

The typical solution of the upper orifice and suction pipe for circulation water usually means a non-movable upper orifice and suction pipe (no pontoons) or at least a shape of the upper orifice which does not restrict turbulent and convective heat transport in the buffer layer of the steam cushion system.

Below, two different operation cases (heating season and summer season) of the steam cushion system were analyzed for the Bialystok CHPp.

1) $T_{a}=100^{\circ} \mathrm{C}, T_{b}=98^{\circ} \mathrm{C}, i_{h t}=4.5, D_{\text {int }}=21 \mathrm{~m}, \delta=0.887 \mathrm{~m}, \lambda=0,68 \mathrm{~W} /(\mathrm{m} \cdot \mathrm{K})$

$$
\begin{gathered}
\dot{q}=\frac{\lambda}{\delta}\left(T_{a}-T_{b}\right) \cdot i_{h t}=\frac{0.68}{0.887}(100-98) \cdot 4.5=6.9 \mathrm{~W} / \mathrm{m}^{2} \\
\dot{Q}=\dot{q} \cdot \frac{\pi \cdot D_{i n t}^{2}}{4}=6.9 \cdot \frac{\pi \cdot 21^{2}}{4}=2389 \mathrm{~W} \\
T_{c}=100-\frac{\dot{q} \cdot \delta_{1}}{\lambda \cdot i_{h t}}=100-\frac{6.9 \cdot 0,2}{0.68 \cdot 4.5}=99.5^{0} \mathrm{C}
\end{gathered}
$$

2) $T_{a}=100^{\circ} \mathrm{C}, T_{b}=70^{\circ} \mathrm{C}, i_{h t}=4.5, D_{\text {int }}=21 \mathrm{~m}, \delta=0.887 \mathrm{~m}, \lambda=0,68 \mathrm{~W} /(\mathrm{m} \cdot \mathrm{K})$ (the worst case, happened during the summer season)

$$
\begin{gathered}
\dot{q}=\frac{\lambda}{\delta}\left(T_{a}-T_{b}\right) \cdot i_{h t}=\frac{0.68}{0.887}(100-70) \cdot 4.5=103.5 \mathrm{~W} / \mathrm{m}^{2} \\
\dot{Q}=\dot{q} \cdot \frac{\pi \cdot D_{\text {int }}^{2}}{4}=103.5 \cdot \frac{\pi \cdot 21^{2}}{4}=35830 \mathrm{~W} \\
T_{c}=100-\frac{\dot{q} \cdot \delta_{1}}{\lambda \cdot i_{h t}}=100-\frac{103.5 \cdot 0.2}{0.68 \cdot 4.5}=93.3^{0} \mathrm{C}
\end{gathered}
$$


In the proposed technical solution of a movable suction pipe for circulation water, fixed to the pontoon preserve, the inlet of the pipe is located at a constant level approx. $0.2 \mathrm{~m}$ from the surface of the water in the tank. The temperature of the circulation water in the suction pipe could not drop below $99.5^{\circ} \mathrm{C}$ (when hot water in the TES tank is at $98^{\circ} \mathrm{C}$ - typical operation case) or $93.3^{\circ} \mathrm{C}$ (when hot water in the TES tank is at $70^{\circ} \mathrm{C}-$ a hypothetical case that does not exist in reality) as is presented in equations (4) and (7) accordingly.

\section{Summary and conclusions}

The steam cushion system generates energy savings by using an appropriate technical solution for the upper orifice and suction pipe for circulation water, i.e. to make it movable through the use of pontoons. Where an upper orifice is used, an isolating buffer layer is created at the top of the tank with very restrained convective and turbulent heat transport, thereby causing limited heat transfer from the steam bed area to the water in the tank. The thickness of the buffer layer, which isolates the surface of the water from the rest of the water in the TES tank, is usually 0.8 to $1 \mathrm{~m}$. Water is a relatively good isolator, with thermal conductivity on average of approx. $0.68 \mathrm{~W} /(\mathrm{m} \mathrm{K})$, and if it is possible to keep convective and turbulent heat transport in the buffer layer to a minimum, then heat flux from condensing steam will be limited. In that case heat flux is approximately one-tenth of the heat flux that occurs in the typical technical solution of the upper orifice and suction pipe for circulation water in the TES tank.

\section{Nomenclature}

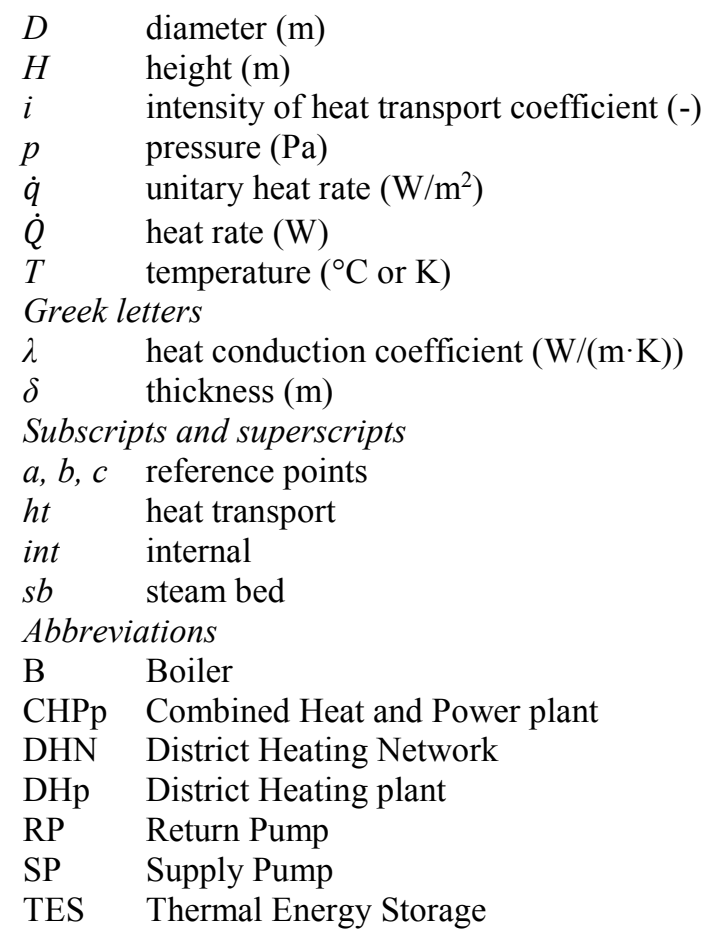




\section{References}

1. I. Dincer, S. Dost, X. Li, Int. J. Energy Res. 21, 1157 (1997)

2. I. Dincer, Energy Build. 34, 377 (2002)

3. I. Dincer, Int. J. Energy Res. 26, 567 (2002)

4. I. Dincer, S. Dost, X. Li, Int. J. Global Energy Issues 9, 351 (1997)

5. R. Zwierzchowski, E3S Web Conf. 22, 00296 (2017)

6. R. Zwierzchowski, Politechnika Warszawska, Prace Naukowe, Inzynieria Srodowiska 64, 1-136 (2013)

7. Y. Zurigat, A. Ghajar, P. Moretti, Appl. Energy 30, 99 (1988)

8. Y. Zurigat, P. Liche, Int. J. Heat Mass Transfer. 34, 115 (1991)

9. F. Oppel, A. Ghajar, P. Moretti, ASHRAE Trans. 92, 293 (1986)

10. M. Wildin, ASHRAE Trans. 96, 1, 1094 (1990)

11. M. Wildin, ASHRAE Trans. 102, 2, 123 (1996)

12. S. Murthy, J. Nelson, T. Rao, Solar Energy 49, 273-277 (1992)

13. I. Dincer, M. A. Rosen, Thermal Energy Storage. Systems and Applications (2 ${ }^{\text {nd }}$ ed., John Wiley \& Sons, Ltd., Chichester, England, 2011)

14. P. Votsis, S. Tason, D. Wilson, C. Marquand, Journal of Mechanical Engineering Science 202, 187 (1988) 